\title{
O papel da amizade ao longo do ciclo vital
}

\author{
Juliane Callegaro Borsa - Pontificia Universidade Católica do Rio de Janeiro, Rio de Janeiro, Brasil
}

Souza, L. K. Hutz, C. S. (Org.). (2012). Amizade em contexto: desenvolvimento e cultura. São Paulo: Casa do Psicólogo.

A amizade é reconhecida na literatura científica como uma importante fonte de felicidade e de bemestar subjetivo, uma vez que proporciona o suporte social, o compartilhamento de experiências, de interesses, de sentimentos e de emoções (Cheng, \& Furnham, 2002; Hartup, 1996). As relações de amizade permitem ao indivíduo o aprendizado de habilidades sociais importantes para o estabelecimento de relações interpessoais satisfatórias e harmoniosas ao longo de todo o ciclo vital. Entende-se a amizade como uma interação íntima, espontânea e recíproca entre duas pessoas, caracterizada por um forte componente afetivo (Bukowski e cols., 1996).

A obra Amizade em Contexto: desenvolvimento e cultura, de autoria de Luciana Karine de Souza e Claudio Simon Hutz, lançada pela Casa do Psicólogo em 2012, é uma importante reflexão sobre a importância da amizade para o desenvolvimento humano, pois propõe uma discussão para além das relações e vínculos estabelecidos na infância e na adolescência, abordando a amizade na idade adulta e na velhice. O livro é composto por oito capítulos que trazem as contribuições de importantes profissionais e pesquisadores da área. Conta com o prefácio do professor doutor Cílio Ziviani. Em sua introdução, o professor Cilio salienta que a obra oferece uma discussão multidisciplinar sobre a amizade, integrando conhecimentos da psicologia, da filosofia, da antropologia e da sociologia, contribuindo com informações teóricas e práticas.

No primeiro capítulo, "Uma bistória do conceito de amizade", de autoria de Luciana Karine de Souza e Gustavo Gauer, os autores discutem as contribuições filosóficas, antropológicas e religiosas pertinentes à compreensão do conceito de amizade e revisam os estudos empíricos sobre o tema, no âmbito da psicologia. Concluem que a amizade é um conceito complexo e multifacetado e que conta com diversas definições. Embora seja um campo recente de investigação, os autores apontam para o crescente interesse, por parte dos pesquisadores, na compreensão teórica e empírica da amizade.

No segundo capítulo "Amizade na criança pequena: padrões de interação e diferenças de gênero", de Patrícia Ruschel Daudt, Luciana Karine de Souza e Tânia Mara Sperb, são discutidas as características de interação e de formação de laços de amizade em crianças pré- escolares. Para ilustrar a discussão, as autoras apresentam resultados de uma pesquisa com crianças portoalegrenses, em que foram investigadas as características da interação verbal e não-verbal entre pares considerando o tipo de vinculo (amigo/nãoamigo) e gênero (masculino e feminino). As autoras destacam a importância da interação entre pares para o desenvolvimento infantil e discutem diferenças de gênero e de padrões de interação verbal e não-verbal em crianças pré-escolares.

De autoria de Carolina Lisboa, o terceiro capítulo, "Quem tem um amigo nunca está sozinho? Ou antes só do que mal acompanhado? Relações de amizade: fatores de risco e proteção", versa sobre a amizade enquanto importante fator de proteção ao longo do desenvolvimento. A autora salienta que a ausência de laços de amizade pode se configurar como fator de risco para problemas emocionais e comportamentais. Apresenta as contribuições da Psicologia Positiva para a compreensão da amizade e para a promoção de políticas públicas e intervenções clínicas que visem aos aspectos saudáveis do desenvolvimento humano.

No capítulo "As relacooes de amizade de futuros pais adolescentes", as autoras Vanessa de Castilhos Susin e Daniela Centenaro Levandowski discutem as mudanças nas relações de amizade entre jovens, quando estes se tornam pais. As autoras abordam as mudanças na qualidade das interações e os sentimentos positivos e negativos dos pares frente à paternidade e suas consequências (aumento de responsabilidades, mudanças de papeis, entrada no mercado de trabalho, entre outros). Apresentam uma revisão da literatura sobre a amizade na adolescência e os resultados de uma pesquisa qualitativa que investigou em seis pais adolescentes as particularidades e as mudanças nas suas relações de amizade.

No quinto capítulo, intitulado "As relações de amizade na velhice", Regina Maria Prado Leite Erbolato discute a importância do contato social nesta etapa do ciclo vital. Com base nos resultados de uma pesquisa por ela desenvolvida, a autora apresenta as expectativas dos idosos ante as suas relações sociais. Discute a amizade, as perdas, as expectativas de futuro, a escolha dos parceiros afetivos e a importância das redes sociais na velhice à luz da Teoria da Seletividade Socioemocional e do Modelo de Comboio das Relações Sociais. 
O sexto capítulo, "A construção da moral, dos valores e da amizade", de Jussara Cristina Barboza Tortella, trás uma reflexão sobre o desenvolvimento dos valores morais inerentes à amizade, a partir de uma perspectiva construtivista piagetiana. Apresenta, também, os resultados de estudos sobre o desenvolvimento da moralidade e dos valores e discute o papel das interações sociais na construção moral. A temática é ilustrada pelos dados de uma pesquisa conduzida pela autora, que contou com 154 crianças e objetivou compreender as representações de meninos e meninas em relação ao grau de amizade e de fidelidade estabelecido com seus pares.

As relações humanas no ambiente de trabalho é o tema do sétimo capítulo, intitulado "Amizade, trabalho e bem-estar subjetivo". A autora Adriana Kipper-Smith apresenta uma reflexão sobre as relações humanas, contextualizando-as a partir dos valores e características do contexto laboral e fundamentando-as segundo os pressupostos filosóficos de Platão, Aristóteles, Cícero, São Tomé de Aquino e Santo Agostinho. A autora apresenta, ainda, os resultados de uma investigação realizada com 60 trabalhadores acerca das concepções e significados das relações de amizade no ambiente de trabalho.

Finalmente, o oitavo capítulo, "Amizades interculturais, interétnicas, inter-raciais e internacionais", de Agnaldo Garcia e Raquel Ferreira Miranda, discute a amizade entre indivíduos de diferentes culturas, etnias, raças e nacionalidades. Conta com uma revisão da literatura sobre o tema, o qual, segundo os autores, é, ainda, carente de pesquisas. Os estudos descritos mostram as semelhanças e as diferenças nas relações de amizade estabelecidas em diferentes contextos culturais. Os autores apresentam dados de um estudo sobre a amizade, que contou com 10 universitários moçambicanos residentes no Brasil.

A obra Amizade em contexto: desenvolvimento e cultura apresenta uma discussão rica sobre um tema ainda recente nas pesquisas em psicologia, sobretudo no Brasil. Em tempos de tamanha ênfase nos problemas de interação, em que crescem as investigações sobre bullying, assedio moral, fobia social, solidão, entre outros problemas de interação, ainda são escassas as discussões sobre os aspectos positivos concernentes à interação humana, como é o caso da amizade e dos valores éticos, sociais, afetivos e morais nela envolvidos. Essa obra configura-se como um importante passo em direção a esse novo olhar.

\section{Referências}

Bukowski, W. M., Newcomb, A. F., \& Hartup, W. W. (eds.) (1996). The company they keep: friendship in childhood and adolescence. Cambridge, University Press, p. 1-15.

Cheng, H., \& Furnham, A. (2002). Personality, peer relations, and self-confidence as predictors of happiness and loneliness. Journal of Adolescence, 25(3), 327-339.

Hartup, W. W. (1996). The company they keep: friendships and their developmental significance. Child Development, 67(1), 1-13.

Sobre a autora:

Juliane Callegaro Borsa é psicóloga, mestre em Psicologia Clínica (PUCRS) e doutora em Psicologia (UFRGS). professora assistente do Departamento de Psicologia, da Pontifícia Universidade Católica do Rio de Janeiro (PUCRJ).

\section{Contato com a autora:}

Pontifícia Universidade Católica do Rio de Janeiro

Rua Marquês de São Vicente, 225 - Edifício Cardeal Leme Gávea - CEP 22451-900 - Rio de Janeiro/RJ, Brasil E-mail: juliborsa@gmail.com 